\title{
Literature Review on the Development of Public-Private- Partnership Leisure Sightseeing Agriculture
}

\author{
Yuexia $\mathrm{WU}^{1}$, Xiuping $\mathrm{WANG}^{1}$ \\ ${ }^{1}$ Jiangsu University of Science and Technology, Zhenjiang, Jiangsu, China
}

\begin{abstract}
Comprehensive use of content analysis method and quantitative visualization analysis method, taking journal papers and master's thesis in the field of PPP of CNKI database as samples, through content analysis of research topics, research nature, and analysis of authors, literature discipline distribution, research hotspots and other fields, To discuss the trend characteristics of research and development in the field of PPP leisure agriculture in my country.
\end{abstract}

\section{Introduction}

Against the background of the new crown pneumonia epidemic, my country's agricultural development has ushered in huge challenges, and the financial pressures of local governments have intensified. Leisure sightseeing agriculture as an important means of agricultural transformation and upgrading and the PPP model as a tool to relieve government finances, the integration of the two opens up a new path for agricultural development. In April 2020, the Ministry of Agriculture and Rural Affairs issued the "Guidelines for Social Capital Investment in Agriculture and Rural Areas", which emphasized the need to guide social capital to develop rural characteristic cultural industries. However, the use of the PPP to develop leisure tourism agriculture is still in its infancy and lacks sufficient theory to guide it. Therefore, it is particularly important to conduct relevant research on related issues in this field at this time.

By consulting the literature, it is found that since the introduction of relevant policies in 2015 , relevant research in this field has appeared in the academic community. Although relevant studies have been done on the feasibility of the PPP model and its role, it has not been paid much attention to in summarizing the research framework and development trend of PPP leisure tourism agriculture. Additionally, the literature reviewed and summarized at present is the analysis and research of journal literature, and there is a certain degree of subjectivity. This article will use a combination of qualitative analysis and quantitative analysis to more objectively analyze the research content analysis category system, research methods and properties, and research hotspots of my country's PPP literature, with a view to contributing to the development of my country's PPP leisure tourism agriculture. Construction and research provide theoretical reference and practical guidance.

\section{Research methods and data selection}

\subsection{Research method}

This paper mainly adopts the method of combining content analysis and quantitative visualization analysis to analyze the relevant literature in the field of PPP leisure and tourism agriculture from different angles in an allround way. Based on the combination of content analysis method and quantitative visualization analysis method, this paper combs the related literature of PPP leisure tourism agriculture in a comprehensive and systematic manner. For content characteristics such as research topics, research methods, and research nature, the content analysis method is mainly used, combined with the use of visualization atlas for deeper analysis; for the external characteristics of the literature, the distribution of research time, the distribution of active authors, and research hotspots, the quantitative visualization method is mainly used.

\subsection{Data selection and statistics}

In order to ensure the reliability of subsequent analysis, the accuracy of the previous data collection should be ensured. Therefore, this article selects the authoritative CNKI database and retrieves it from journal papers and master and doctoral papers. The main keywords are "PPP" and "Leisure Tourism Agriculture". Considering the different opinions of different authors on the same concept, the synonyms of the keywords should also be considered. After restrictions under relevant conditions, 51 journal papers and 13 master and doctoral papers were initially obtained. After carefully studying the relevant literature, it is found that some of the documents in the search results belong to non-academic research papers such as conference notices, or their research content has nothing 
to do with PPP leisure tourism agriculture research. Therefore, it is necessary to eliminate the unmatched documents, and finally obtain 32 valid journal documents, 6 master and doctoral papers.

\section{Content analysis and statistical description}

\subsection{Research evolution path}

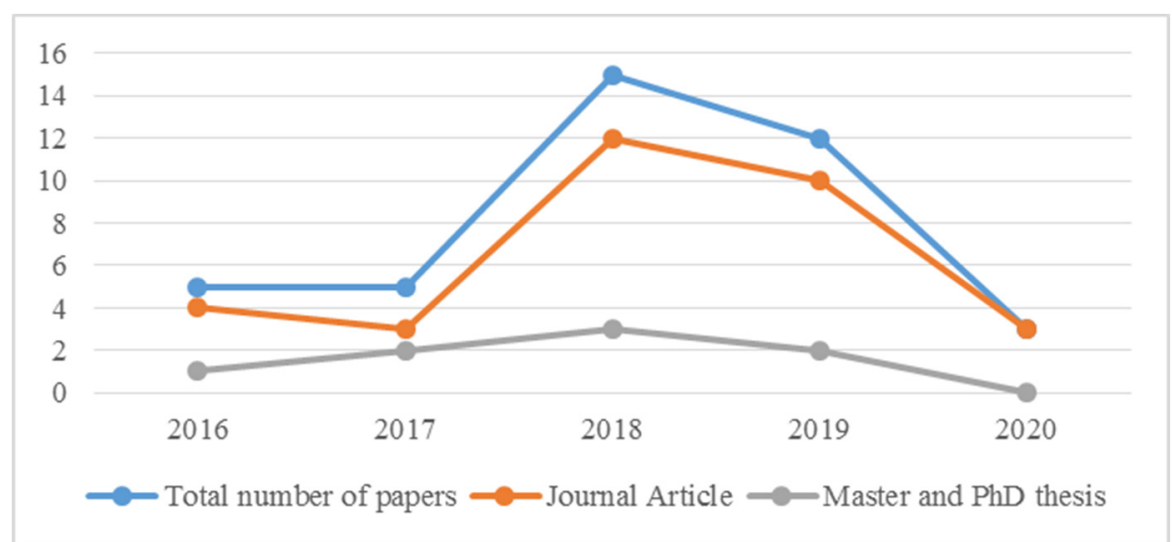

Figure 1. Trends of publications in the field of PPP leisure tourism agriculture

Figure 1 shows the trend of publications in the field of PPP leisure tourism agriculture. From the perspective of the overall amount of publications, there are few research literatures on PPP leisure tourism agriculture, but there are obvious differences between different types of papers. Among them, there are a large number of journal papers, and only a few master and doctoral papers have conducted related research in this field. Judging from the time of publication of the paper, related research in this field did not appear until 2016. This is mainly due to the short time for the PPP model to be introduced into the country, and it has just started to be used for the supply of public products and services such as infrastructure, transportation, and medical care. As the application of the PPP model continues to mature and its advantages gradually become prominent, it has successfully promoted the expansion of the PPP model to more fields. Since 2015, the national ministries and commissions have repeatedly issued relevant policies to encourage the use of the PPP model to develop leisure tourism agriculture, which has also prompted the academic community to actively carry out relevant research in this field. Since then, the number of posts in this field has shown a slight increase, and has shown a significant increase in 2018. However, the number of articles published in 2019 and 2020 has declined, mainly because articles usually require a longer review cycle, which makes the publication of articles appear obvious time lag.

\subsection{Research theme and nature analysis}

The content analysis method generally first classifies the literature research content according to the research objectives, and then analyzes the objective characteristics of different classifications, and then records them into a category table. Based on the category system adopted by relevant scholars, this article divides the document samples to be studied into research topics and research nature category systems. Table 1 is the relevant situation of the research topic, and Table 2 is the situation of the research nature category system. Since the use of PPP recreational sightseeing agriculture project itself is the application of the PPP model, therefore, journal papers and master and doctoral papers are applied to solve practical problems. Research and comprehensive research focusing on both enriching the knowledge system and solving practical problems.

\begin{tabular}{|c|c|}
\hline Name & Interpretation \\
\hline Background & $\begin{array}{c}\text { Discuss the background and } \\
\text { development history of the development } \\
\text { of leisure tourism agriculture in the PPP } \\
\text { model }\end{array}$ \\
\hline $\begin{array}{l}\text { Feasibility } \\
\text { analysis }\end{array}$ & $\begin{array}{l}\text { Explore the feasibility of using PPP } \\
\text { model to develop leisure and sightseeing } \\
\text { agriculture }\end{array}$ \\
\hline $\begin{array}{l}\text { Influencing } \\
\text { factors }\end{array}$ & $\begin{array}{l}\text { Discuss the impact of various risks } \\
\text { that may occur in the development of } \\
\text { PPP leisure sightseeing agriculture on } \\
\text { the project }\end{array}$ \\
\hline $\begin{array}{l}\text { Policy and } \\
\text { system }\end{array}$ & $\begin{array}{l}\text { guarantee Discuss the role and } \\
\text { significance of national policies in } \\
\text { promoting the development of this field }\end{array}$ \\
\hline $\begin{array}{c}\text { Mode } \\
\text { characteristics }\end{array}$ & $\begin{array}{l}\text { Discuss the different modes and } \\
\text { characteristics of PPP leisure and } \\
\text { sightseeing agriculture }\end{array}$ \\
\hline $\begin{array}{l}\text { Research } \\
\text { on Foreign } \\
\text { Situations }\end{array}$ & $\begin{array}{l}\text { Discuss the overseas development } \\
\text { of PPP leisure tourism agriculture and } \\
\text { what my country can learn from }\end{array}$ \\
\hline $\begin{array}{l}\text { Efficiency } \\
\text { and Value }\end{array}$ & $\begin{array}{l}\text { Discuss the coordination efficiency } \\
\text { mechanism of PPP leisure tourism } \\
\text { agriculture multi-parties, and adjust the } \\
\text { industrial structure, the positive } \\
\text { significance of cultural protection and } \\
\text { rural revitalization }\end{array}$ \\
\hline $\begin{array}{c}\text { Case } \\
\text { Application } \\
\text { Study } \\
\end{array}$ & $\begin{array}{l}\text { Research on the case application of } \\
\text { PPP leisure tourism agriculture }\end{array}$ \\
\hline Other & $\begin{array}{l}\text { Articles that cannot be accurately } \\
\text { classified in any of the above categories }\end{array}$ \\
\hline
\end{tabular}


Table2. Literature research nature category system

\begin{tabular}{|c|c|c|}
\hline $\begin{array}{c}\text { Research } \\
\text { Nature }\end{array}$ & Interpretation & Corresponding Subject \\
\hline Basic research & $\begin{array}{c}\text { Points to theory, reveals universality } \\
\text { and regularity, and aims at enriching the } \\
\text { knowledge system of the subject. }\end{array}$ & $\begin{array}{c}\text { Discussion on the operation mode of } \\
\text { PPP leisure sightseeing agriculture }\end{array}$ \\
\hline Applied research & $\begin{array}{c}\text { Points to the actual existing problems, } \\
\text { with the purpose of solving real problems. }\end{array}$ & $\begin{array}{c}\text { The application of the PPP model in this } \\
\text { field is to explore the situation of different } \\
\text { regions and different projects. }\end{array}$ \\
\hline $\begin{array}{c}\text { Comprehensive } \\
\text { research }\end{array}$ & $\begin{array}{c}\text { points to the above two contents, the } \\
\text { purpose is to solve practical problems by } \\
\text { theoretical rules, }\end{array}$ & $\begin{array}{c}\text { project management, risk management, } \\
\text { financing mode, etc. }\end{array}$ \\
\hline
\end{tabular}

\section{Visual analysis of research hotspots}

\subsection{Keyword cluster analysis}

Cluster analysis is performed on the basis of a frequency matrix. Therefore, it is necessary to construct a frequency matrix in the early stage of data processing. However, in order to show the implicit relationship between keywords,

a similarity matrix is generally needed to eliminate the frequency difference. This article uses SATI software to count the frequency of keywords appearing in the literature and generate a $50 \times 50$ matrix. The partial data of similar matrix is shown in Table 3 . The data in the table indicates the correlation coefficient between each keyword. The larger the coefficient, the stronger the correlation. If the similarity matrix contains too many 0 values, it is not conducive to the accuracy of statistics, and the dissimilarity matrix is usually used instead.

Table3. Similarity matrix constructed by sample documents (partial)

\begin{tabular}{|c|c|c|c|c|c|c|}
\hline & PPP model & $\begin{array}{c}\text { Pastoral } \\
\text { complex }\end{array}$ & $\begin{array}{c}\text { Rural } \\
\text { tourism }\end{array}$ & $\begin{array}{c}\text { PPP financing } \\
\text { model }\end{array}$ & $\begin{array}{c}\text { Rural } \\
\text { revitalization }\end{array}$ & $\begin{array}{c}\text { Operation } \\
\text { model }\end{array}$ \\
\hline PPP model & 1 & 0.2121 & 0.1488 & 0 & 0.0952 & 0 \\
\hline Pastoral complex & 0.2121 & 1 & 0 & 0.0455 & 0.0455 & 0.1818 \\
\hline Rural tourism & 0.1488 & 0 & 1 & 0.0625 & 0.0625 & 0 \\
\hline $\begin{array}{c}\text { PPP financing } \\
\text { model }\end{array}$ & 0 & 0.0455 & 0.0625 & 1 & 0 & 0.25 \\
\hline $\begin{array}{c}\text { Rural } \\
\text { revitalization }\end{array}$ & 0.0952 & 0.0455 & 0.0625 & 0 & 1 & 0 \\
\hline Operation model & 0 & 0.1818 & 0 & 0.25 & 0 & 1 \\
\hline
\end{tabular}

\subsection{Keyword co-occurrence map network}

Through the study of keyword knowledge graphs, complex knowledge can be displayed through data mining, information processing, knowledge measurement and graph drawing, revealing the development laws of knowledge fields, and providing practical and valuable references for subject research. This paper analyzes the literature through SATI software, and obtains a network map of keywords in the field of PPP leisure tourism agriculture. The size of the node in the graph is related to the frequency of keyword appearance. The higher the frequency of appearance, the larger the node, and the more research times, which intuitively reflects the distribution of current research hotspots. It can be seen from the map that current research mainly focuses on the exploration of the model of rural complex development under the PPP model, the exploration of the model based on the perspective of rural revitalization, the impact of the development of leisure agriculture and rural tourism on traditional culture, and the application of specific cases of PPP leisure tourism agriculture. And other hot topics. 


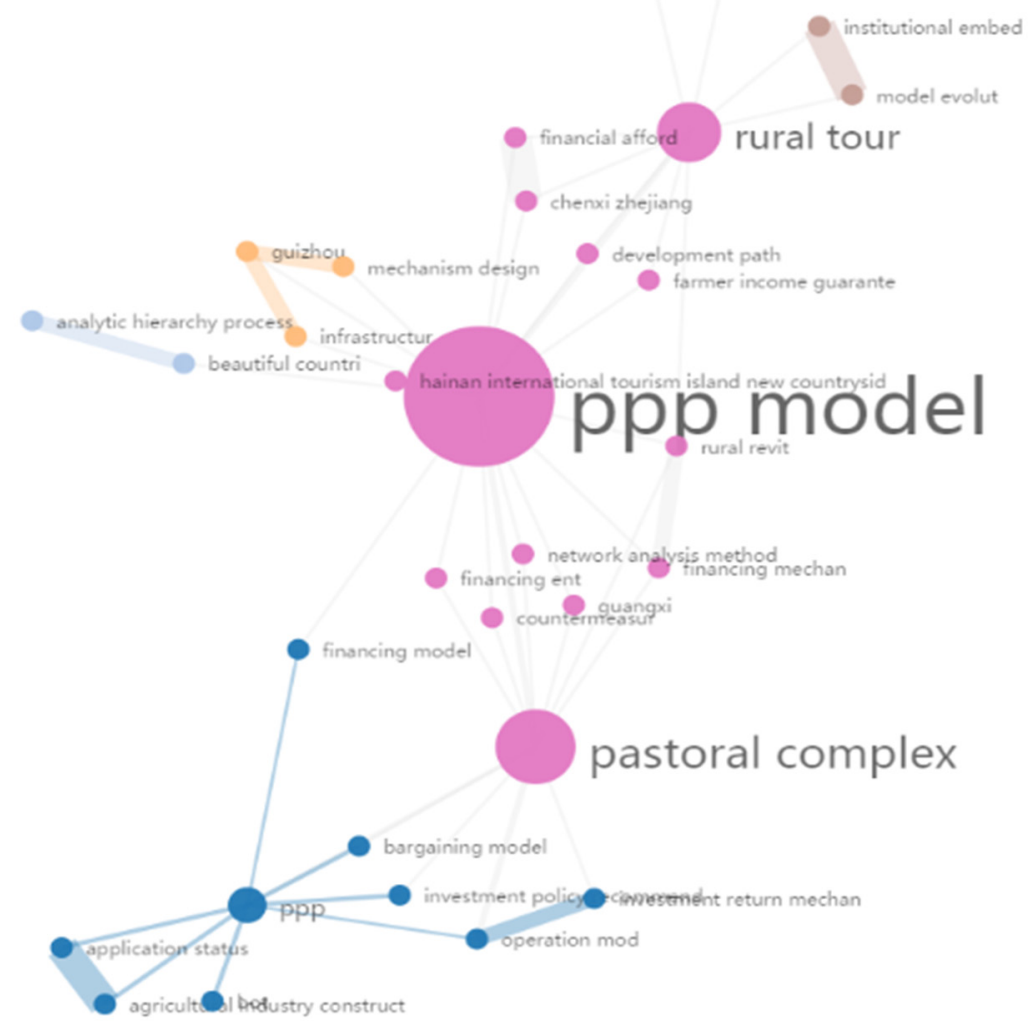

Figure 2. Knowledge graph of keywords

\section{Conclusion and inspiration}

The conclusion can be summarized as the following:

(1) Scholars' research on PPP leisure and sightseeing agriculture is more inclined to comprehensive research. In recent years, as the PPP model has gradually matured in the theoretical and practical circles, the PPP model has expanded to more fields. The focus of scholars' research has shifted from the general issues of decision-making and risk sharing under the PPP theory and PPP model in the early stage to exploring new issues arising from PPP in new application scenarios. Therefore, future scholars' research in this field will still focus on comprehensive research that combines knowledge systems and solving practical problems.

(2) The research of PPP leisure tourism agriculture presents a research trend of obvious interdisciplinary distribution. Scholars in different fields have obvious differences in their thinking about problems. Most of them look for, analyze and solve problems based on their own professional perspectives. Therefore, in the future, scholars of different disciplines should be encouraged to conduct research on related issues in this field from different perspectives.

(3) The research hotspots of PPP leisure and sightseeing agriculture mainly have positive effects on rural agriculture and the government. But for the standardization of the system and the decision-making of the main body have few related documents such as optimization. Therefore, future scholars should continue to explore areas that have not yet been studied while maintaining their existing research advantages.

\section{Project fund format description}

This article is one of the phased achievements of the graduate student innovation project "PPP Leisure Sightseeing Agriculture Project Main Body Investment Strategy Research" (KYCX20_3170).

\section{References}

1. Zhenhua WANG, Qian XU, Jinhe GAO. Risk assessment of decision-making stage beautiful village PPP project based on analytic hierarchy process $[\mathrm{J}]$. Journal of East China University of Technology (Social Science), 2019, 38(04):343-347.

2. Hui CAO. Status and Orientation of Promoting Cooperation between Government and Social Capital in Agriculture Sector [J]. Reform, 2019(02):64-73.

3. Mingli WANG. The Application of PPP Financing Mode to the Rural Complex and its Risk Prevention and Control [J]. Journal of Jilin Financial Research, 2018(06):50-54.

4. Xiaofan WANG. Research on PPP Financing Mode of Rural Tourism in Underdeveloped Regions [J]. Chinese \& Foreign Entrepreneurs, 2018(14):49+182.

5. Lulu HE. Application Research of infrastructure PPP mode based on new urbanization in Guizhou Province [D]. Guizhou University, 2018.

6. Shengying DUAN. Research on the Application of PPP Mode in Rural Tourism Industry [J]. Modern Economic Information, 2018(07):393. 
7. Chunhong WU. Study on the Risk Evaluation of the PPP Project of Beautiful Village Construction under the Guidance of Tourism Development [D]. Wuhan University of Technology, 2018.

8. Rui SUN. Study on Government Behavior of the PPP Mode-Tasking Rural Tourism Project of Binzhou Economic and Technological Development Zone as an Example [D]. Shandong University, 2018.

9. Yubo MA, Ailiang XIE. Research on the Promotion and Inheritance of Tea Culture in the Construction of Tea Garden Complex [J]. Journal of Agricultural Management Institute of Ministry of Agriculture and rurial Affairs, 2018(01):22-24.

10. Ying ZHANG. Use PPP investment to help the construction of rural complex [J]. Contemporary Rural Finance and Economics, 2018(02):13-14. 